\title{
Oyuncak ile meydana gelen kesici-delici beyin dokusu yaralanması
}

\section{Penetrating brain injury caused by a toy}

\section{Türker Karancı, Aydın Canpolat, Hakan Duman, Ali Kaan Kılınç, Ali Osman Akdemir, Ünal Özüm*}

Nöroşirürji Kliniği (Dr. T. Karanc1), Özel Medicana Hastanesi, TR-34310 İstanbul, Nöroşirürji Kliniği (Dr. A. Canpolat, Dr. H. Duman, Dr. A. K. Kılınç, Dr. A. O. Akdemir), Taksim Eğitim ve Araştırma Hastanesi, TR-34433 İstanbul, Beyin ve Sinir Cerrahisi Anabilim Dalı (Doç. Dr. Ü. Özüm), Cumhuriyet Tıp Fakültesi, TR-58140 Sivas

\section{Özet}

Çocukluk çağının ikinci en sık ölüm nedeni kafa travması sonrası gelişen ağır beyin hasarlarıdır. Dört yaş altı çocuklar çocukluk çağı kafa travmasında en yüksek risk grubunu oluşturur. Kafa kemiklerinin tam gelişmemiş olması delici-kesici beyin dokusu yaralanmaları için kolaylaştırıcı bir durumdur. Elinde oyuncağı olduğu halde yüksekten düşme sonrası elindeki oyuncağın sebep olduğu delici-kesici beyin dokusu yaralanması ile acile başvuran ve ameliyat edilerek sorunsuz bir şekilde taburcu edilen 18 aylık kız çocuğu olgusu sunulmuş ve literatür bilgileri ile birlikte tartışılmıştır.

Anahtar sözcükler: Kafa travması, delici-kesici beyin dokusu yaralanmaları

\begin{abstract}
Severe traumatic brain injuries following head trauma are the second most common cause of death in pediatric population. Especially children younger than the age of four years are under the highest risk for head trauma among all pediatric patients. The incomplete development and ossification of calvarial bones facilitates traumatic brain injuries due to penetrating insults. Herein we present an 18-months-old girl, who was operated for severe penetrating brain injury due to a fall from heights and discharged from the hospital without any deficits or complications. The toy that the patient was holding in her hand was the cause of the penetrating brain injury. The case was discussed according to the data in the current literature.
\end{abstract}

Keywords: Head trauma, penetrating brain injuries

Geliş tarihi/Received: 30 Ocak 2013; Kabul tarihi/Accepted: 26 Temmuz 2013

*İletişim adresi:

Dr. Ünal Özüm, Beyin ve Sinir Cerrahisi Anabilim Dalı, Cumhuriyet Tıp Fakültesi, TR-58140 Sivas. E-posta: sofamor@gmail.com

\section{Giriş}

Kafa travması sonrası görülen ağır beyin hasarı çocukluk çağının en sık ikinci ölüm nedenidir. Bu döneminde görülen ölümcül kafa travması nedenleri ise araç içi ya da dışı trafik kazaları, düşmeler, yürüteç kazaları ve delici-kesici kafa yaralanmalarıdır. Delicikesici beyin dokusu yaralanmaları ateşli silah, kesici ev ya da mutfak aletleri ile olabileceği gibi tornavida ya da oyuncak gibi başka nesnelerle de olabilir [1].

\section{Olgu sunumu}

18 aylık kız çocuğu tekerlekleri çıkık halde oyuncağ 1 ile birlikte yüksekten düşmesi sonrası tekerleğin metal tutucusu kafanın ön bölgesine saplanmış halde acil servise başvurdu. Fizik muayenesinde sağ frontalde orta hatta yakın metal kısmın cilde saplı 
olduğu oyuncak tespit edildi (Resim 1). Nörolojik muayenesi normal olarak değerlendirilen hastanın çekilen direkt grafisinde ve bilgisayarlı beyin tomografisinde (BBT) sağ frontalde yabancı cismin kemik ve durayı geçerek forntal loba yaklaşı 3-4 cm girdiği tespit edildi (Resim 2,3). Ameliyata alınan hastanın kafasına penetre olan yabancı cisim çıkarıldı ve durası tamir edildi. Ameliyat sonrası nörolojik muayenesi ve kontrol BBT'si normal olan hasta taburcu edildi.

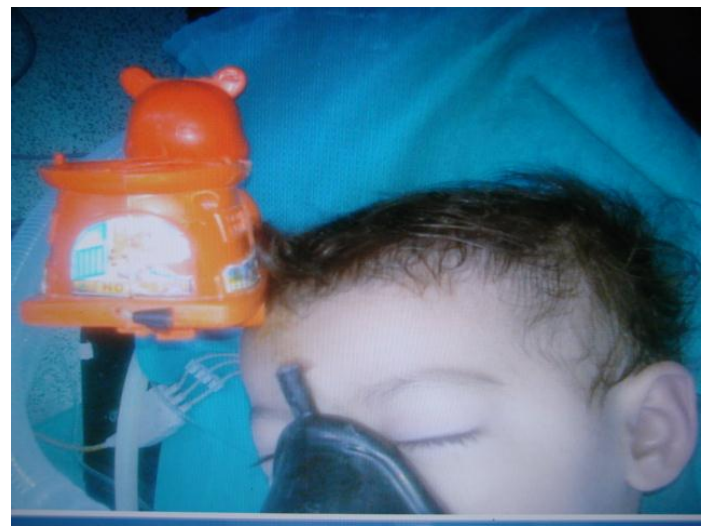

Resim 1. Başın sağ ön kısmına saplanmış oyuncağın görüntüsü.

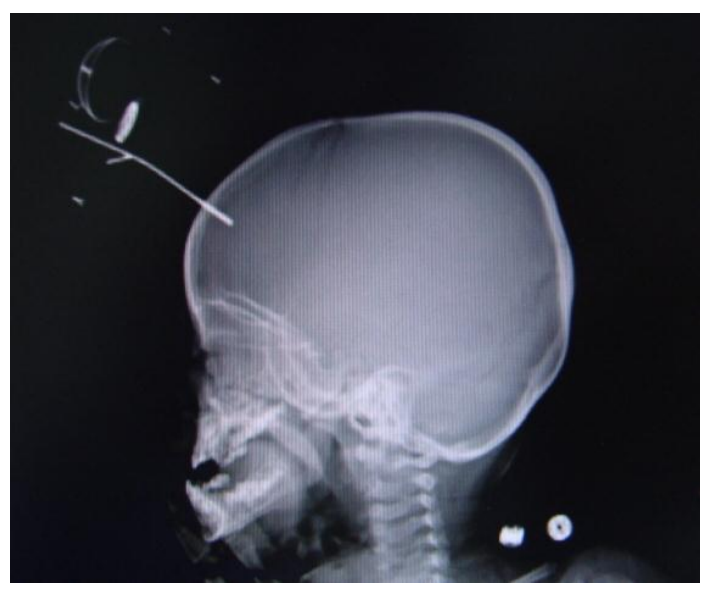

Resim 2. Lateral direkt grafide frontal kafa kemiğini geçerek kafa içerisine girmiş metal yabancı cismin görüntüsü.

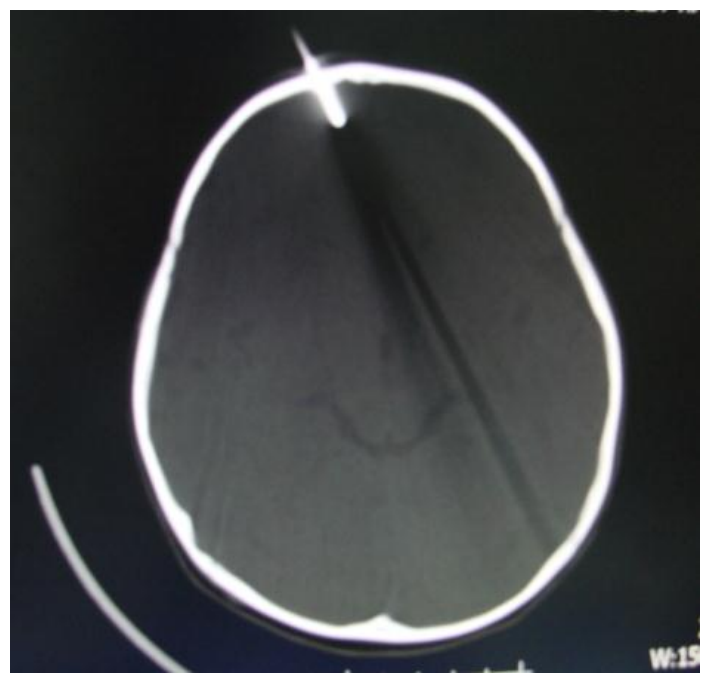

Resim 3. Bilgisayarlı beyin tomografisinde sağ frontal loba saplanmış olmuş metal yabanı cismin görüntüsü. 


\section{Tartıșma}

Dünyada her yıl yaklaşık beş milyon çocuk kafa travması nedeni ile acil servislere başvurmaktadır [3]. Çocukluk çağı kafa travmasında en yüksek risk grubu ilk dört yaş grubudur, bu yaş grubunda yıllık kafa travması sıklığ 1035/100000, hastaneye yatırılma oranı 80/100000, ölüm oranı 5,7/100000'dir [1]. Çocukluk çağı kafa travmaları ölümcül çocuk kazalarının \% 40’’nı oluşturur. Bu ölümler sıklıkla taşıt araçlarına bağlı kazalar, düşmeler, yürüteç kazaları, paten-kızak ve kaydırak kazaları, oyuncak kazaları ve boğulma nedenlidir. Binek oyuncak araç, oyuncak tırnak, askı, çivi ve kurdele toplar en s1k travmaya yol açmaktadır. Yine aynı dönemde yaklaşık 220050 oyuncağa bağlı travmatik yaralanma olduğu ve bunun 165100 ünün 15 yaş altında olduğu bildirilmiştir. $\mathrm{Bu}$ travmalar baş ve yüz en s1k etkilenen bölgeler olmak üzere kesi, çürüme ve abrazyondur. Erkek çocuklar yaklaşık \%60 sıklıkla travmaya maruz kalmaktadır [2]. Oyuncağın neden olduğu travma yaklaşık \%50 baş ve yüz bölgesinde görülür, ağız, gözler ve kulaklar en sik etkilenmektedir [2, 3].

Özellikle oyuncakların sert, sivri veya keskin kenarları ile oluşabilecek kranial veya orbital yaralanmaların sonuçları son derece ciddi olabilir ve literatürde bir çok örneği vardır. Böyle durumlarda genellikle basit müdahaleler ile tedavi mümkün olabilse de kesici-delici yaralanmalarda cerrahi müdahale gerekebilir. Ayrıca bu tip travmaların beraberinde getirdiği enfeksiyon riski ve diğer komplikasyonlar ile olası vasküler yaralanmalar durumu daha da kötüleştirebilir. Çocukluk dönemi kafa travması, erişkin dönemle karşılaştırıldığında sonuçları genelde daha iyi olduğu görülmektedir. Ancak ağır kafa travması okul öncesi çocuklarda daha ciddi sonuçlara yol açmaktadır [2].

Bizim olgumuzda ilk bakışta zararsız görülebilen oyuncağın tekerleğinin çıkması sonucu metal parça açıkta kalmış ve hasta elinde oyuncakla düşerek yaralanma meydana gelmiştir. Kraniumun delici-kesici yaralanmasının olduğu durumlarda cerrahi öncesi planlama ve tetkikler eksiksiz ve dikkatle yapılmalıdır. Operasyon sırasında da kanama kontrolü hassasiyetle gerçekleştirilerek; nöral dokular dikkatle korunmalı, ameliyat sonrasında operasyon sahası gerekli nöroradyolojik tetkikler ile gözden geçirilmeli ve profaktik antimikrobiyal tedavi uygulanmalıdır [1].

Çocukluk döneminde oyuncak yaralanmaları önceden tahmin edilmesi oldukça zor olabilir ve en zararsiz görünen oyuncaklarla bile son derece ciddi travmalar meydana gelebilir. Basit önlemlerle bu yaralanmalarının çoğunun önüne geçilebilir.

\section{Kaynaklar}

1. Gürelik M, Kars HZ. Çocukluk Çağı Kafa Travmaları. Kaya Aksoy (ed). Temel Nöroşirurji 2. Baskı Ankara: TND Yayınları, 2010; s: 613-24.

2. Boran BO, Boran P, Barut N, Akgun C, Celikoglu E, Bozbuga M. Evaluation of mild head injury in a pediatric population. Pediatr Neurosurg 2006; 42: 203-7.

3. Önal ÇS. Çocukluk Çağı Kafa Travmaları.Türkiye Klinikleri J Neurosurg-Special Topics 2008; 1: 72-82. 